\title{
Location-based social networking media for restaurant promotion and food review using mobile application
}

\author{
H.S. Luhur ${ }^{1}$, N.D.Widjaja ${ }^{2}$ \\ ${ }^{1,2}$ Bina Nusantara University, School of Information Systems, 12270 Jakarta, Indonesia. Email: \\ hendryc_satya@yahoo.com, nwidjaja@,binus.edu
}

\begin{abstract}
This paper is focusing on the development of a mobile application for searching restaurants and promotions with location based and social networking features. The main function of the application is to search restaurant information. Other functions are also available in this application such as add restaurant, add promotion, add photo, add food review, and other features including social networking features. The restaurant and promotion searching application will be developed under Android platform. Upon completion of this paper, heuristic evaluation and usability testing have been conducted. The result of both testing shows that the application is highly usable. Even though there are some usability problems discovered, the problems can be eliminated immediately by implementing the recommendations from the expert evaluators and the users as the testers of the application. Further improvement made to the application will ensure that the application can really be beneficial for the users of the application.
\end{abstract}

\section{Introduction}

The advancement of mobile technology has brought smart phone technology into existence. The wide functionalities of smart phone have made it accepted rapidly by the users. It is estimated that the number of smart phone users in Indonesia will increase by $460 \%$ from July 2011 up to July 2012 [1]. The majority of smart phone market share in Indonesia is now dominated by Android OS by having 56\% of the market share [2].

As the effect of growing number of smart phone users, the number of mobile application to be installed and used for the smart phone is also increasing rapidly. By the year of 2011, there were only 200,000 applications in Google Play Store, an application store for Android smart phone. In 2012, however, the number of applications has reached more than 675,000 applications [3]. One of the fastest growing segments in the application store is restaurant application. It is supported by the fact that Apple has just created the food and drinks category in its application store to facilitate the increasing number of food and drinks application in which it contained 9,000 applications as of July 2012 [4].

This data indicates that there is a changed culture regarding food. A research by Flowtown [5] shows that before and during meals, $40 \%$ of consumers learn about food through website, apps, or blogs and $21 \%$ look up discounts on food. In addition, there is a new culture that people consume food not only to fulfill the needs of the body but also to enjoy and experience it as an art. People love to take picture of the foods as the evidence of what they enjoyed [6]. On a routine basis, $25 \%$ will share the food photograph through social networks [5].

Existing application that allow people to search for restaurant using location-based service, or to search for discounts, or to read and submit food review, or to take picture and share to friends have been available. However, there has never been a compact media that integrates all of the features in a single application. The users have to switch between applications to fulfill their needs toward food and discounts.

The purpose of this paper is therefore to analyze and design a location based social networking media, specifically for restaurant promotion and restaurant search using mobile application for Android. This project will integrate the features of existing applications that were developed separately. By providing this system, it is expected that people can have seamless information in one application to help them socialize, search restaurants, learn about food, as well as enjoy discounts and promotions. 


\section{Theoretical Foundations}

\subsection{Mobile Application}

The increasing number of the mobile devices users has lead to the growing number of application developed for mobile devices (often referred to as mobile application). Mobile application (apps) is application software that is designed to run on mobile devices such as smart phone [7]. The applications provide similar services with applications in the computer, but with less functionality. The applications have to be downloaded from the app store to be able to be used. Application store (app store) is an online store where mobile applications are available to be purchased and downloaded [8]. Usually, each mobile operating system will have its own app store. Apple App Store and Android Google Play are two of the largest app store currently.

\subsubsection{The Rise of Food Related Mobile Application}

One of the most developed applications nowadays is food related application. In 2012, Apple even launched food and drink category in the app store due to the increasing number of the app. Apple described the food and drink category as "apps that help users cook and bake, mix drinks, manage recipes, find new restaurants and bars, and learn what their friends like to eat and drink" [9]. Apps for diet, coupon clipping, grocery shopping, and food-related games will not be included in this category. It is reported that there were more than 9,000 applications in this category as of July 2012 [9].

Based on the description of the food and drink category above, there are several types of applications that fall under this category, which are:

\section{- Restaurant and dish review}

This type of application allows users to submit review of the restaurant they have been visited and the food they have tasted. Foodspotting is the example of the global application and Toresto is the example of the local application.

\section{- Restaurant search}

This type of application allows users to manually discover restaurant by typing specific search criteria such as restaurant name, restaurant address, or type of food. Recent applications utilize GPS technology that allows users to search for nearby restaurants based on their location. According to the research by xAd and Telmetrics [10], location is the main reason that makes smart phones users visits the restaurant after they search it. Usually, the feature of restaurant and food review and restaurant search is combined into one application such as in Open Rice Indonesia and Makan Di Mana.

\section{- Recipe}

This type of application provides a database of food and drink recipes and the ingredients to help the users in cooking dishes or making the drinks. Stepby-step explanation is usually used to guide the users. Users can also choose based on the type of food they would like to cook, for instance vegetarian food. The example of this type of application is Masak Apa.

\subsection{Location-based Service}

The increasing population of mobile phone and mobile Internet users has made it possible for users to request service based on their location information. For instance, it is possible for users to search for nearby restaurants or get the directions to the restaurants based on their location. Such service is often referred as location-based service. Virrantaus et al [11] defined location-based service as "Information services accessible with mobile devices through the mobile network and utilizing the ability to make use of the location of the mobile device".

There are 5 basic components of a location-based service, which are [12]:

- Mobile devices

Tools that the users use to request for information. The devices that can be used are mobile phone and navigation unit.

- Communication network

Network for interchanging data and service request between mobile device and service provider.

- Positioning components

Components for determining the location of the users such as mobile network and Global Positioning System (GPS).

- Service provider

Provides different services to the users by processing the service request. Finding route is one example of the possible services.

- Data and content provider

The geographical data and location information will usually not provided by the service provider. The service provider will request the data to the parties who own it.

\subsection{Social Network Site}

Social network has become the inseparable part of most people life. Since its first emergence twenty years ago, social network is still continue to grow. Social network offer the users a new way to socialize, interact, and engage with people, events, and brands without being constrained by the geographic boundaries. Currently, there are many definitions of social network site but according to Boyd and Ellison [13], which definition is amongst the most cited, the definition of social network site is:

"Web-based services that allow individuals to (1) construct a public or semi-public profile within a bounded system, (2) articulate a list of other users 
with whom they share a connection, and (3) view and traverse their list of connections and those made by others within the system. The nature and nomenclature of these connections may vary from site to site."

Based on the definition, social network site help people to engage with their connections in the virtual world through online profile. The profile is a page where users can put their personal data to represent their online presence. The profile owner can choose to whom they want to share their profile with, either to the public or only to their friends or connections.

Nowadays, social networking site is growing very fast and has become part of the lifestyle of most people. In Indonesia, $89 \%$ of Internet users visit social media sites [15]. This makes Indonesia become the fourth largest Facebook users in the world with more than 47 million users [14]. Based on this data, social networking site has become one of the fastest growing segments of the Internet, especially in Indonesia. Moreover, there is also a trend in Indonesia towards mobile social networking in which $89 \%$ of the Internet users access social media sites from their phone [15]. This data indicates that the future of social networking sites will be in the form of mobile application.

\subsection{Location-based Social Network}

The presence of location-based services for mobile devices and the growth of social networking site have lead to the development of a new concept of social network called location-based social network.

According to Y.Zheng as quoted by Microsoft Research [16], the definition of location-based social network is:

"A location-based social network (LBSN) does not only mean adding a location to an existing social network so that people in the social structure can share location-embedded information, but also consists of the new social structure made up of individuals connected by the interdependency derived from their locations in the physical world as well as their location-tagged media content, such as photos, video, and texts."

Typical location-based social networking site allow the users to do 'check-in'. The check-in in location-based social network is the process of determining the position of current user and posting the geographical location to the social media. Users can do the check-in through text messaging (using Cell ID as the positioning method) or directly through the applications in their smart phone (using GPS or A-GPS as the positioning method).

To build location-based mobile apps specifically for Android, Google provides Google Maps Android API. With Google Maps Android API, it is possible to add Google Maps data to an Android application. The API will control the access to the servers, download data, display map, and respond to map gestures [17]. The API can also be used to add markers, polylines, polygons, ground overlays, and tile overlays to the maps.

\subsection{Testing}

The testing methods that are going to be used in this project are heuristic evaluation and usability testing. The consideration for selecting the testing methods is based on the evaluation's criteria, experts' availability, skills, experience, availability of the users, and availability of time for the test administrator to conduct the testing.

In addition, a repetitive studies by Desurvire [18], Jeffries [19], and Karat [20] shows that both heuristic evaluation and usability testing acts as complementary to each other to find out the usability problems that can be eliminated to increase the chance of success instead of showing repetitive findings [21]. Moreover, Holzinger [22] suggested that using two or more methods for testing would lead to a more accurate result because more issues can be discovered.

The models are used to represent abstract things such as actors, activities, business process, and relationship between data. UML diagrams that will be used in this project consist of activity diagram, use case diagram, data flow diagram, and entity-relationship diagram.

\subsubsection{Heuristic Evaluation}

Heuristic evaluation is "a systematic inspection of a user interface design for usability" [23]. There are so called expert evaluators in heuristic evauation. Expert evaluators are the people who have the skills and experience regarding usability and user interface domains [24]. The expert evaluators will be doing the heuristic evaluation to find out the usability problems of the system by rating the 10 heuristics developed by Rolf Molich and Jakob Nielsen [25] [26] [27]. The Nielsen's Ten heuristic is as follow :

- Visibility of System Status.

- Match between System and The Real World.

- User Control and Freedom.

- Consistency and Standards.

- Error Prevention.

- Recognition Rather Than Recall.

- Flexibility and Efficiency of Use.

- Aesthetic and Minimalist Design.

- Help Users Recognize, Diagnose, and Recover from Errors.

- Help and Documentation.

\subsubsection{Usability Testing}

The second method of testing used in this project is usability testing. In usability testing, the future users of the application will be involved to do the testing. The purpose of usability testing is to test the usability, learn ability, and user-friendliness of the mobile application. 
All templates for the usability testing sessions are derived from [28].

During the testing session, the test administrator explained the test session and test scenarios, and asks the participants to fill in brief background questionnaire. The participants then read the test scenarios and try to complete the tasks.

After each task, the test administrator asked the participant to rate the interface on a 5-point Likert scale (Strongly Disagree to Strongly Agree). Post-task scenario subjective measures includes:

- How easy it was to do the task?

- How easy it was to accurately predict icons/ buttons to do the task?

- How easy it was to identify your current location in the website?

After the last task is completed, the test administrator asked the participant to rate the application overall by using a 4-point rating scale (Strongly Disagree to Strongly Agree) for five subjective measures including:

- Ease of use - how easy it was to use the application.

- Frequency of use - how frequent will the user use the application.

- Learn ability - how easy it would be for most users to learn to use the application.

- Look \& feel appeal - the content of the main menu content makes the users want to explore the site further.

- Usefulness - is the application useful for the users.

In the end, the test administrator asked the participants the following overall application questions:

- What the participant liked most.

- What the participant liked least.

- Recommendations for future improvement.

\section{Problem Analysis}

In Indonesia, there are several famous applications that provide information regarding food and restaurant which are Makan Di Mana, Toresto, and Open Rice Indonesia. In addition, there are also well-known global applications that provide similar services. Global applications are the applications developed by companies outside Indonesia but the application is accessible across the globe. The example is Foodspotting.

The four applications mentioned above have been tested and were proven to have strengths and weaknesses in terms of the features provided. A table of comparison below will be used to compare the features of each existing application with the new proposed features of Foodeals application. Table 1 shows that all of the existing applications are not having complete features while Foodeals will integrate all of the features into one application.

In addition, based on the result of a market survey conducted through online questionnaire, it shows that the future users of the application were all agreed to have all of the lacking features of the existing applications combined into an application that can be their one-stop restaurant and promotion discovery application without having to access more than one application anymore.

So, for this project, the outcome will be a new system with integrated features of existing applications. The features are:

- Search restaurant using GPS

- Search discount and promotion information

- All search results contained in a map

- Accurate and complete search results

- Search restaurant using specific search criteria

- Take food picture

- Add restaurant information

- Add food review

- Photo gallery

- Comment on friend's photo

- Share photo with friends

- View friend's activity

- Comment on friend's activity

\section{Solution Design}

\subsection{Business Model}

Business Model Canvas developed by A. Osterwalder [29] will be used as the template in defining the business model for this project as shown in Table 2 .

\subsection{Alternative Solutions}

There are two alternatives to choose in developing the final product of this project, to build for Android or Blackberry platform. The comparison between the alternatives is shown in Table 3. 
Table 1. Comparisons of existing applications

\begin{tabular}{|c|c|c|c|c|c|}
\hline \multirow{2}{*}{ Comparison (Features) } & \multirow{2}{*}{$\begin{array}{c}\text { Proposed App } \\
\text { Foodeals }\end{array}$} & \multicolumn{4}{|c|}{ Existing Application } \\
\hline & & Toresto & Makan Di Mana & Open Rice ID & Foodspotting \\
\hline Focus & Food only & Food only & Food only & Food only & Food only \\
\hline Base & Indonesia & Indonesia & Indonesia & Indonesia & San Fransisco \\
\hline Search Nearby & Yes & Yes & Yes & Yes & Yes \\
\hline Advanced search & Yes & No & Yes & Yes & No \\
\hline Food discount information & Yes & Yes, but not clear & Yes, but no result & Yes, but no result & $\begin{array}{l}\text { Yes, but no } \\
\text { result }\end{array}$ \\
\hline Map containing all results & Yes & No & No & Yes & Yes \\
\hline Take picture & Yes & Yes & Yes & Yes & Yes \\
\hline Add restaurant & Yes & Yes & Yes & No & Yes \\
\hline Add food review & Yes & Yes & No & Yes & Yes \\
\hline Users Profile & Yes & No & No & No & Yes \\
\hline User Activity & Yes & No & No & No & Yes \\
\hline User Photo Gallery & Yes & No & No & No & No \\
\hline Add Friends & Yes & No & No & No & Yes \\
\hline $\begin{array}{l}\text { Comment on friend's } \\
\text { activity }\end{array}$ & Yes & No & No & No & Yes \\
\hline Platform & Android & $\begin{array}{l}\text { Android, iOS, } \\
\text { Windows Phone }\end{array}$ & $\begin{array}{c}\text { Android, iOS, } \\
\text { Blackberry }\end{array}$ & $\begin{array}{c}\text { Android, iOS, } \\
\text { Blackberry }\end{array}$ & $\begin{array}{c}\text { Android, iOS, } \\
\text { Windows Phone, } \\
\text { Blackberry }\end{array}$ \\
\hline
\end{tabular}

Table 2. Business Model

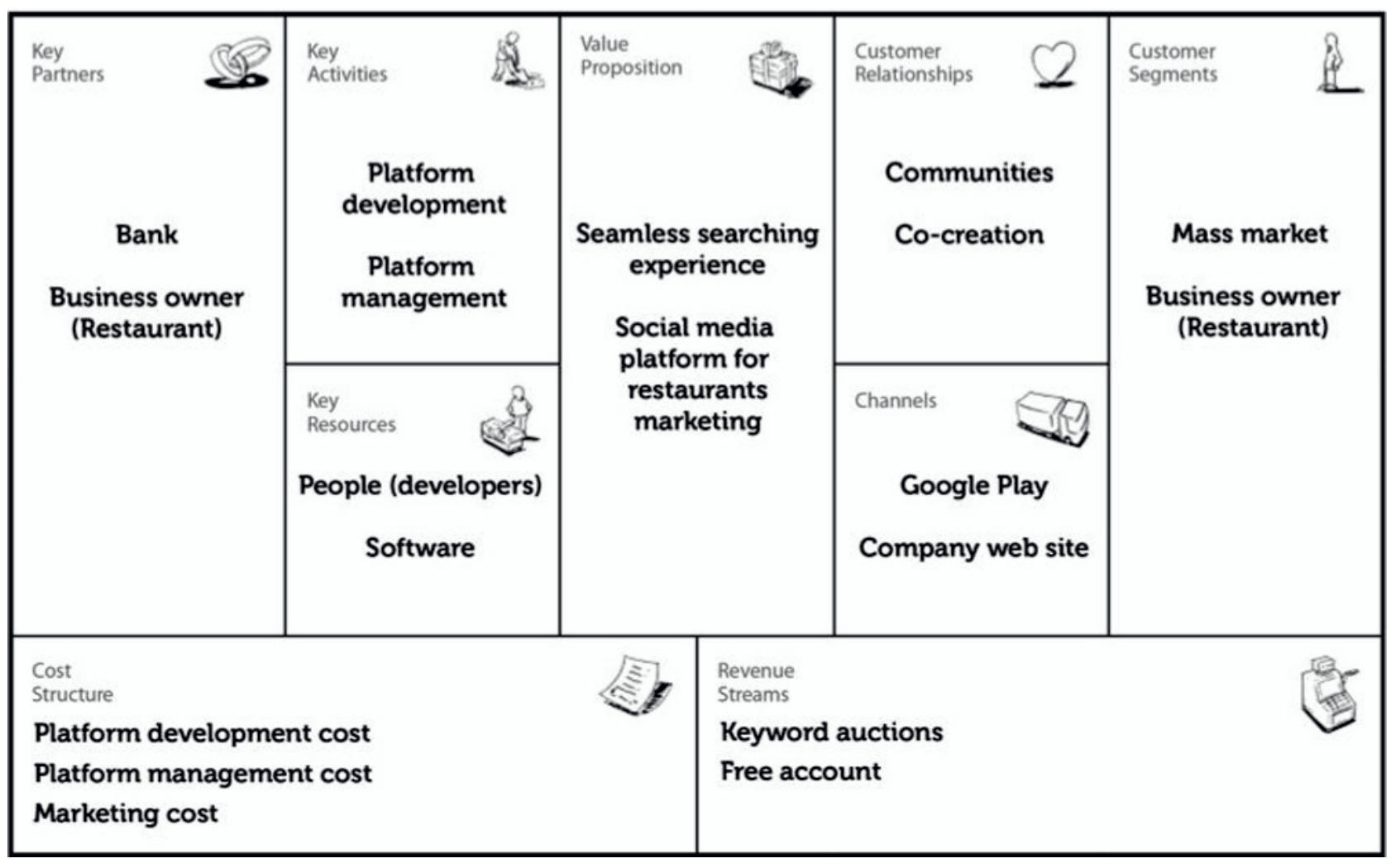


Table 3. Comparison between alternative solutions

\begin{tabular}{|l|c|c|}
\hline \multicolumn{1}{|c|}{ Comparison } & Android & Blackberry \\
\hline Market Share & $\begin{array}{c}56 \% \text { (in } \\
\text { Indonesia) }\end{array}$ & $37 \%$ (in Indonesia) \\
\hline Platform & Open platform & Open platform \\
\hline $\begin{array}{l}\text { Development } \\
\text { language }\end{array}$ & Java & $\begin{array}{c}\text { Java, Native C, } \\
\text { HTML5, }\end{array}$ \\
\hline $\begin{array}{l}\text { Development } \\
\text { software }\end{array}$ & $\begin{array}{c}\text { Free Standard } \\
\text { Development Kit } \\
\text { (SDK) }\end{array}$ & $\begin{array}{c}\text { Free Standard } \\
\text { Development Kit } \\
\text { (SDK) }\end{array}$ \\
\hline $\begin{array}{l}\text { Adding app to } \\
\text { the app market }\end{array}$ & $\begin{array}{c}\text { One-time fee for } \\
\text { \$25 }\end{array}$ & Free \\
\hline $\begin{array}{l}\text { App } \\
\text { distribution }\end{array}$ & $\begin{array}{c}\text { Google Play Store } \\
\text { and APK file }\end{array}$ & $\begin{array}{c}\text { Blackberry App } \\
\text { World and JAD file }\end{array}$ \\
\hline
\end{tabular}

In conclusion, developing for both Android and Blackberry has the same advantages for the developers. Even though Android is slightly more expensive and can only use Java programming language, an Android app can reach more users than a Blackberry app due to its higher market share. So, based on the comparison, it is decided that the final product of this project will be an Android mobile application.

\subsection{Context Diagram}

Context Diagram is a high level diagram showing the overall interaction occuring between the actors and the system. The Context Diagram of the system design for this project is shown in Figure 1.

\section{Testing and Implementation}

\subsection{Implementation Strategy}

The implementation phase of this project is divided into two phases. The most important features that will be prioritized in the first implementation phase are :

- Search restaurant using GPS

- Search discount and promotion information

-All search results contained in a map

-Accurate and complete search result

-Search restaurant using specific search criteria

-Take food picture

-Add restaurant information

-Add food review

-Photo gallery

While for additional features such as comment on friend's photo, share photo with friends, view friend's activity and comment on friend's activity will be developed in the second phase.

\subsection{Testing}

\subsubsection{Heuristic Evaluation}

Table 4 shows the detailed result of the heuristic evaluation by the expert evaluators on Foodeals. From the evaluation, 19 problems were discovered of which there are $53 \%$ of cosmetic problems and $47 \%$ of minor problems. No major or even catastrophic problem found in this application.

Table 4. Result of Heuristic Evaluation

\begin{tabular}{|l|c|c|c|c|c|}
\hline \multicolumn{1}{|c|}{ Ten Nielsen Heuristics } & Cosmetic & Minor & Major & Catastrophic & Total \\
\hline Visibility of System Status & 2 & 2 & - & - & 4 \\
\hline Match between System and The Real World & 1 & - & - & - & 1 \\
\hline User Control and Freedom & 2 & 2 & - & - & 4 \\
\hline Consistency and Standards & 2 & 1 & - & - & 3 \\
\hline Error Prevention & - & - & - & - & 0 \\
\hline Recognition Rather Than Recall & 2 & 1 & - & - & 3 \\
\hline Flexibility and Efficiency of Use & - & 3 & - & - & 3 \\
\hline Aesthetic and Minimalist Design & 1 & - & - & - & 1 \\
\hline Help Users Recognize, Diagnose, and Recover from Errors & - & - & - & - & 0 \\
\hline Help and Documentation & - & - & - & - & 0 \\
\hline Number of problems discovered & $\mathbf{1 0}$ & $\mathbf{9}$ & $\mathbf{0}$ & $\mathbf{0}$ & $\mathbf{1 9}$ \\
\hline Percentage of problems discovered & $\mathbf{5 3 \%}$ & $\mathbf{4 7 \%}$ & $\mathbf{0 \%}$ & $\mathbf{0 \%}$ & $\mathbf{1 0 0 \%}$ \\
\hline
\end{tabular}


ICASCE 2013

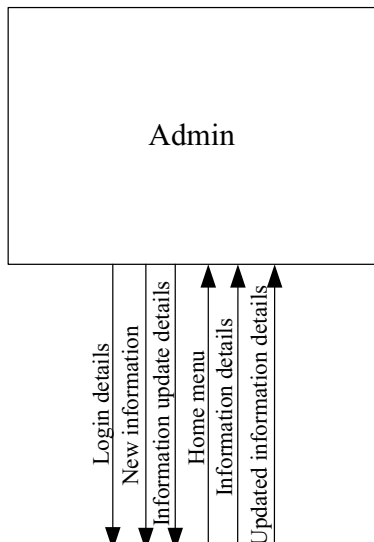

User

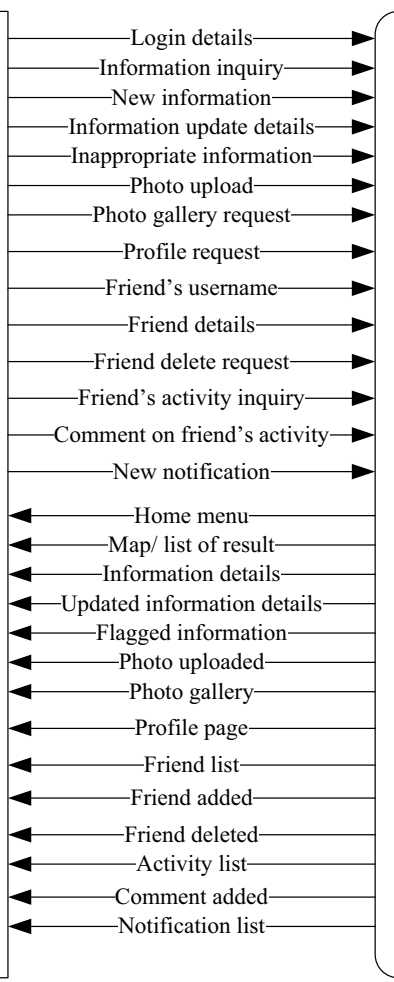

$\nabla v$
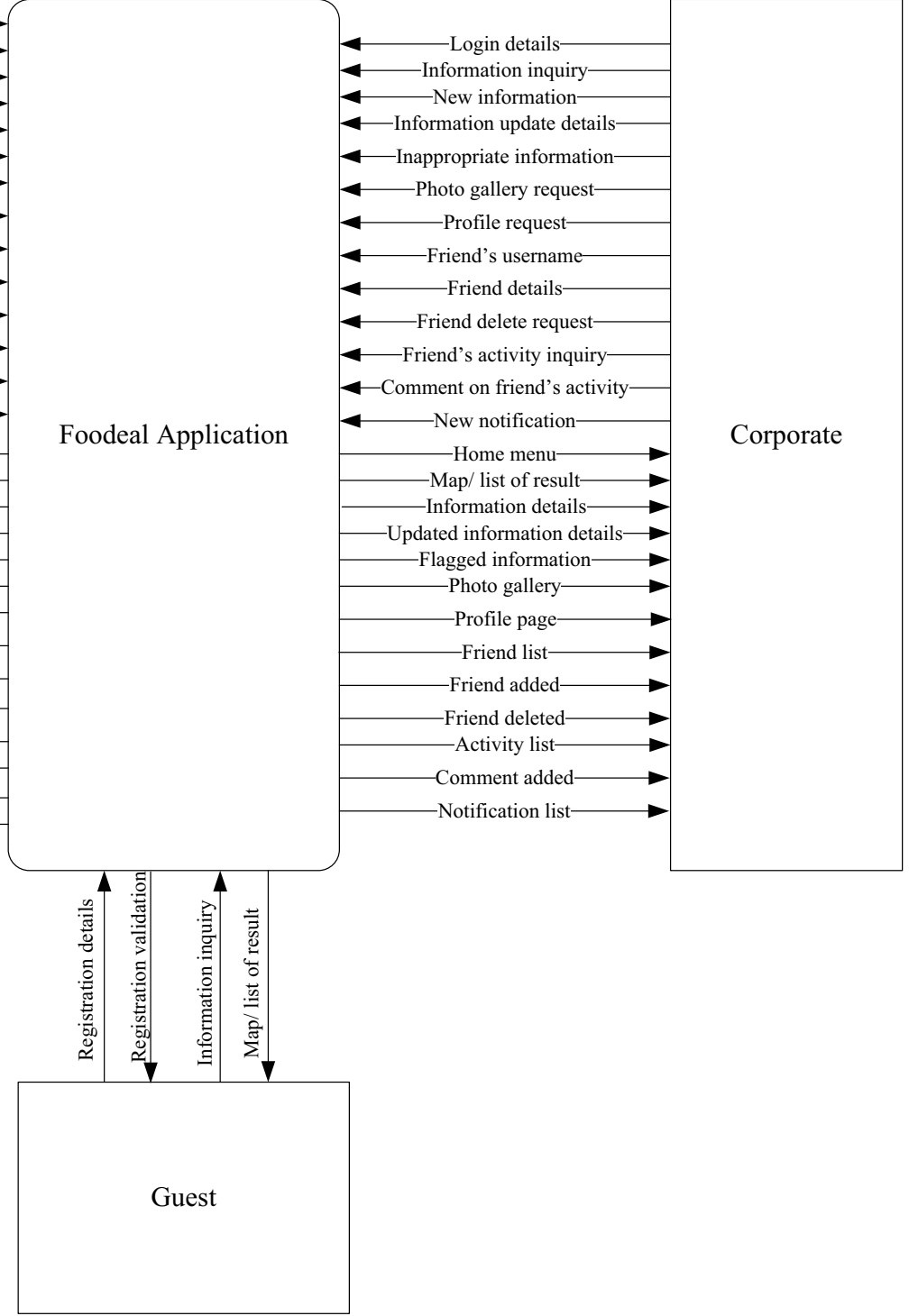

Fig. 1. Context Diagram 


\subsubsection{Usability Testing}

To test the prototype, this project uses some test scenarios and the participants should attempt to complete the tasks from the home menu of the Foodeals prototype. The task scenarios can be seen in Table 5. During the testing session, the task completion, time on task, and error are recorded and the participant will be asked for mean satisfaction rating question after each task and overall rating question after the last task is completed.

Table 5. Task Scenarios

\begin{tabular}{|c|l|}
\hline No & \multicolumn{1}{|c|}{ Tasks } \\
\hline 1 & Search Nearby (Map view) \\
\hline 2 & Search Nearby (List view) \\
\hline 3 & Search (Advanced search) \\
\hline 4 & Register as Personal User \\
\hline 5 & Register as Corporate User \\
\hline 6 & Sign In \\
\hline 7 & View Profile \\
\hline 8 & Edit Profile \\
\hline
\end{tabular}

\begin{tabular}{|c|l|}
\hline 9 & Switch Profile to Photo Gallery \\
\hline 10 & View Friends \\
\hline 11 & Add Friend \\
\hline 12 & View Restaurant Detail \\
\hline 13 & View Restaurant Photo Gallery \\
\hline 14 & Add Restaurant \\
\hline 15 & Update Restaurant \\
\hline 16 & View Promotion Detail \\
\hline 17 & Add Promotion \\
\hline 18 & Update Promotion \\
\hline 19 & Add Food Review \\
\hline 20 & Add Photo from Camera \\
\hline 21 & Add Photo from Photo Library \\
\hline 22 & Sign Out \\
\hline
\end{tabular}

The result summary of the usability testing which consisted of task completion, time on task, errors, and mean satisfaction rating can be seen in Table 6 and the overall rating can be seen in Table 7 .

Table 6. Summary of Usability Testing Result

\begin{tabular}{|c|l|c|c|c|c|}
\hline No & \multicolumn{1}{|c|}{ Tasks } & Task Completion & Errors & Time on Task & Satisfaction* \\
\hline 1 & Search Nearby (Map view) & 5 & 0 & 9.46 & 5 \\
\hline 2 & Search Nearby (List view) & 5 & 0 & 16.9 & 4.87 \\
\hline 3 & Search (Advanced search) & 5 & 0 & 26.1 & 4.87 \\
\hline 4 & Register as Personal User & 5 & 0 & 38.19 & 5 \\
\hline 5 & Register as Corporate User & 5 & 0 & 37.36 & 5 \\
\hline 6 & Sign In & 5 & 0 & 18.44 & 5 \\
\hline 7 & View Profile & 5 & 0 & 9.63 & 5 \\
\hline 8 & Edit Profile & 5 & 0 & 17.48 & 4.93 \\
\hline 9 & Switch Profile to Photo Gallery & 5 & 1 & 36.36 & 4.93 \\
\hline 10 & View Friends & 5 & 0 & 24.15 & 4.73 \\
\hline 11 & Add Friend & 5 & 0 & 12.39 & 5 \\
\hline 12 & View Restaurant Detail & 5 & 0 & 15.11 & 5 \\
\hline 13 & View Restaurant Photo Gallery & 5 & 0 & 21.07 & 5 \\
\hline 14 & Add Restaurant & 5 & 0 & 25.05 & 4.93 \\
\hline 15 & Update Restaurant & 5 & 0 & 9.97 & 4.87 \\
\hline 16 & View Promotion Detail & 5 & 0 & 23.02 & 5 \\
\hline 17 & Add Promotion & 5 & 0 & 26.4 & 4.93 \\
\hline 18 & Update Promotion & 5 & 2 & 44.65 & 5 \\
\hline 19 & Add Food Review & 5 & 0 & 40.37 & 4.67 \\
\hline 20 & Add Photo from Camera & 5 & 0 & 35.02 & 5 \\
\hline 21 & Add Photo from Photo Library & 5 & 5 & 16.23 & 5 \\
\hline 22 & Sign Out & 5 & 5 & 5 \\
\hline
\end{tabular}


Table 7. Usability Testing Overall Rating

\begin{tabular}{|l|c|c|c|c|c|c|}
\hline \multicolumn{1}{|c|}{ Overall Rating } & $\begin{array}{c}\text { Strongly } \\
\text { Disagree }\end{array}$ & Disagree & Agree & $\begin{array}{c}\text { Strongly } \\
\text { Agree }\end{array}$ & $\begin{array}{c}\text { Mean } \\
\text { Rating }\end{array}$ & $\begin{array}{c}\text { Percent } \\
\text { Agree* }\end{array}$ \\
\hline Ease of use & - & - & - & 5 & 5 & $100 \%$ \\
\hline Frequency of use & - & - & 2 & 3 & 4.6 & $100 \%$ \\
\hline Learn ability & - & - & 1 & 4 & 4.8 & $100 \%$ \\
\hline Look \& feel appeal & - & - & - & 5 & 5 & $100 \%$ \\
\hline Usefulness & - & - & - & 5 & 5 & $100 \%$ \\
\hline Liked Most & $\begin{array}{l}\text { User Interface Design } \\
\text { Complete application features }\end{array}$ \\
\hline Liked Least & \multicolumn{5}{l}{} \\
\hline Recome icons are not easily recognizable \\
Rdd more features including social features
\end{tabular}

\section{Discussion}

The result of the heuristic evaluation shows that Foodeals application is proven to be usable. The evidence of it is that $53 \%$ of the usability problems discovered by the experts were cosmetic problems, which means that the problems may be solved if extra time was available for the project. Another $47 \%$ of the usability problems were minor problems that were low priority problems that need to be solved. No major or even catastrophic problems discovered from the evaluation. However, there were some recommendations from the expert evaluators for the improvement to the Foodeals application.

Some suggestions from the expert evaluators for improving the cosmetic problems are as follow:

1. Show the distance from the user's position to the searched restaurant.

2. Provide progress bar to increase visibility of system status. For example, when user is uploading the food photo, there is progress bar showing whether the progress is completed or not.

3. Provide sorting mechanism so that the users can customize the way they would like to view the search result of the restaurant and/ or promotion. The expert recommends to sort by highest rating.

4. Make the overflow button accessible from any pages within the application.

5. Remove the 'Add Food Review' from the 'Add' button because it is already enough to allow the users to add food review from the restaurant detail.

6. Add navigation tab on all pages. Users may be lost in pages without navigation tab.

7. Redesign the '\$' symbol for adding promotion button because it may have different meaning depending on the user's perception.

8. Redesign compass icon on search pages because it is not really recognizable.

9. Provide more emphasis on links, the '>' symbol may be used.

To improve the minor problems, the expert evaluators also give some suggestions as the following:
1. Provide greetings and/ or tutorial for the first time user.

2. Provide pop-up message when necessary to notify the users.

3. Combine the features of 'Add Friend' and 'Invite Friend' into just 'Add Friend'

4. Redesign icon in the profile page for switching between user activities and photo gallery.

5. Provide button for automatically get the location (longitude and latitude) of the users because manual input is not recommended for users when they want to add new restaurant detail.

6. Provide cancel button for any pages that requires user input because user may not noticed the 'Back' button.

7. Add swipe gesture to switch between tabs.

8. Provide search icon with text box for inputting all search criteria that is accessible from any pages.

9. Add restaurant and promotion on the navigation tab as they are the main functions.

The result of the usability testing by the future users shows that there were two problems from the total of 22 tasks created as the test scenario. However, all of the future users agreed that the Foodeals application is easy to use, easy to learn, useful, and that they will frequently use the application because the look and appeal of the application made them wanted to explore more. The future users also provided some recommendations for the improvement of the application, which are:

1. Provide basic tutorial on how to use the system so that the users will recognize the icon and features of the application.

2. Add more functions/ features to the application.

3. Add social features to the application.

*Snapshot of the interface is available if required 


\section{Conclusion}

The design of the Foodeals application has covered all scope mentioned in the project planning of this paper and has met all the user requirements gathered from survey session. However, there are some problems with the implementation phase of the project in which it is not possible to create a fully running mobile application with the resources and knowledge limitation. Hence, the final product of this project is only in prototype form.

Using the application prototype, heuristic evaluation and usability testing have been successfully conducted and resulted in the discovery of some usability problems with the prototype. The detailed result of the testing can be found in testing section. Overall, the expert evaluators from the heuristic evaluation and the users from the usability testing provided recommendations to redesign some iconography and add more features or functions to the application.

In conclusion, the results of the testing session suggested that there were some problems with the new proposed system. It is advisable to increase the number of expert evaluators for the heuristic evaluation and increase the number of testers for usability testing to get a more thorough feedback from the proposed system. However, by implementing the recommendations from the experts and the users, the usability problems of the prototype can be eliminated so that the next implementation phase of the application may produce an Android mobile application that maximizes user experience.

\section{References}

1. Erry, Jumlah Smartphone di Indonesia Meningkat 460 Persen (2012)

2. B. Einhorn, Indonesians Still Love Their BlackBerrys (2012)

3. K. Vere, Tracking growth: the iTunes app store vs Google Play (2012)

4. Apple Adds 'Food \& Drink' Section to App Store, (2012)

5. J. Dancy, Dine and Dish: Are Social Media and Food the Perfect Pairing (2012)

6. K. Alana, Instagram \& Co.: The Mobile Era of Food Photography (2012)

7. M. Cogert, Mobile Website Or Mobile App: Advantages and Disadvantages Of Both

8. What Is an App Store?
9. Apple Adds 'Food \& Drink' Section to App Store (2012)

10. M. Brandau, Study: Restaurant strategies differ for smartphone, tablet apps (2012)

11. K. Virrantaus, J. Markkula, A. Garmash, Y.Terziyan, Developing GIS-Supported Location-Based Services. In: Proc. of WGIS'2001, 423-432 (2001)

12. S. Steiniger, M. Neun, A.Edwardes, Foundations of Location Based Services

13. D.M. Boyd, N.B. Ellison, Social Network Sites: Definition, History, and Scholarship, 13, 1.

14. Facebook Statistics by Countries (2013)

15. O. Hadiwiyana, Beberapa Data Internet, Social Media, Mobile di Indonesia (2012)

16. Y. Zheng, Location-based social networks: Users. In Computing with Spatial Trajectories (Eds. Springer, 2011)

17. Introduction to the Google Maps Android API v2 Google Maps Android API v2

18. H. Desurvire, J. Kondziela, M. Atwood, People and Computers, VII, 89 - 102 (1992)

19. R. Jeffries, J. Wharton, K. Uyeda, User Interface Evaluation in the Real World: A Comparison of Four Techniques (1991)

20. C. Karat, R. Campbell, T. Fiegel, Comparison of Empirical Testing and Walkthrough Methods in User Interface Evaluation (1992)

21. J. Dykstra, A Comparison of Heuristic Evaluation and Usability Testing: The Efficacy of a DomainSpecific Heuristic Checklist (1993)

22. A. Holzinger, Communication of the ACM, 48, 71-74 (2005)

23. Heuristic Evaluation Articles and Training | Nielsen Norman Group

24. B. Shneiderman, C. Plaisant, Designing The User Interface - Strategies for Effective Human Computer Interaction (2005)

25. J. Nielsen, R. Molich, Heuristic Evaluation of User Interface (1990)

26. J. Nielsen, Usability Engineering (1993)

27. J. Nielsen, Usability Inspection Methods, 25 - 62 (1994)

28. U.S. Dept. of Health and Human Services, The Research-Based Web Design \& Usability Guidelines (2006)

29. A. Osterwalder, Y. Pigneur, Business Model Generation (2009) 